\title{
Study on Rural Bank's Credit Risk Transmission Effect Based on Game Theory
}

\author{
Jian-Guo Wei, Shuang Pan \\ School of Economics, \\ Wuhan University of Technology, \\ Wuhan, China \\ E-mail: weijg@whut.edu.cn, \\ 407888228@qq.com
}

\author{
Shan-Shan Wang \\ School of Economics, \\ Wuhan University of Technology, \\ Wuhan, China \\ Law School, \\ Yunnan Minzu University, \\ KunMing, China \\ E-mail: 617481970@qq.com
}

\author{
Juan Cheng \\ Shenzhen Branch of Shanghai Pudong, \\ Development Bank, \\ Shenzhen, China \\ E-mail: 465551540@qq.com
}

\begin{abstract}
This paper firstly studies the transmission path of rural bank's credit risk, and analyzes the credit risk transmission effects, which include Domino effect, coupling effect and broken window effect, then depicts their behavior and characteristics. Based on game theory, the paper explores the mechanisms to block the three effects respectively by credit review, increasing effective collaterals and credit default penalty. Finally, the paper puts forward suggestions for rural bank's credit risk management in China.
\end{abstract}

Keywords-Rural Bank; Credit Risk; Transmission Effect; Game Theory

\section{PREFACE}

Rural bank targets farmers and small rural businesses, providing them with small loans. Until February 2016, 1,330 rural banks had been set up in China. Rural bank's special customers result in that the characteristics of credit risk's generation and transmission are different from that of large commercial banks. Research on the path and effect of risk transmission is conducive to credit risk management of rural bank.

With respect to studies on credit risk of rural bank, Frederic (1996) [1] stated that vulnerability of banks and other financial institutions came from adverse selection and moral hazard caused by information asymmetry. Matutes (2007) [2] held the opinion that the main cause for credit risk of commercial banks was the combination of market combination and deposit insurance. Wang Fang(2013) [3] thought that information asymmetry was the source of credit risk, and pre-loan adverse selection and post-loan moral hazard led to credit risk of rural bank. Fang Kuangnan(2014) [4] adopted Lasso-logistic method to establish an evaluation model of indicators and a warning model for credit risk. Lei Zhenyou(2013) [5] and Wang Dongdong (2016) [6] pointed out that the main reasons for the generation of credit risk were the poor environment of rural credit, lagging construction of credit system, lacking of risk compensation and dispersion mechanism.
With respect to studies on risk transmission, Balg and Goldfajn(1999) [7] analyzed how risk was transmitted among countries during the financial crisis of southeastern Asia. Kaminsky and Reinhart (2000) [8]

Studied the principle of risk transmission among different countries. Gu Haifeng(2013) [9] established a credit risk transmission system for commercial banks and demonstrated credit risk transmission mechanism under the cooperation of banks and insurance companies. Bai Wenjuan(2013) [10] studied the transmission mechanism of internal interest rate risk in life insurance companies based on Domino effect. Wang Yudong(2014) [11] summarized risk transmission characteristics of innovation capital allocation. Zhang Yuan (2015) [12] discussed conditions, paths and mechanism of financial risk transmission in an open economy.

Many researchers use game theory to study the formation mechanism and defense strategy of credit risk in banking system, while few studies are concerned about transmission effect of credit risk of rural bank. This paper will apply game theory to study how to manage rural bank's credit risk based on its characteristics of transmission path and effect.

\section{CREDIT RISK AND THE TRANSMISSION EFFECT OF RURAL BANK}

\section{A. Credit Risk and its Causes of Rural Bank}

Customers of rural bank are farmers and small businesses. Rural bank's special customers and fragile credit environment lead to that credit risk occurs easily and spreads quickly, and is difficult to evaluate.

The reason why rural bank's credit risk occurs can be concluded from four aspects. Firstly, its customers generally are lack of credit consciousness and effective collaterals. Secondly, the agricultural production is naturally weak so that the worsening of natural and market environment may cause heavy losses and directly influence the borrowers' revenue and repayment ability. Thirdly, financial environment in rural areas is imperfect, for instance the lagging of construction of rural credit and agricultural insurance systems. Lastly, weak risk management awareness as well as the shortage of professionals exists in some rural banks. A simple copy of risk 
control system from large commercial banks does not meet the needs of rural bank.

\section{B. Credit Risk Transmission Effect of Rural Bank}

Transmission effect of rural bank's credit risk is the results of credit risk conducting under a series of interacted factors. These results will be interspersed in the process of risk transmission, and can even become a new risk source, which may result in further conduction of credit risk and more serious consequences.

Borrowers dominate use of funds as soon as they obtain the loan. They might choose to maximize the interests based on known information. When borrowers find out the projects with higher income return than that of loan-contracted projects, they will breach the contracts to invest the high return projects. Then capital flows deviate from rural bank's expectation which may lead to risks.

Even if borrowers use the loan in accordance with the contract, they will still face risks such as the deterioration of natural and economic environment, which may cause adverse changes of market prices for loan-projected products. Borrowers will also suffer from passive default due to losses, which makes rural bank being exposed to credit risk.

When borrowers acquire interests from success investments, they may still face new risk sources. They may hold the opinion that severe punishment will not be implemented by rural bank due to lack of effective collaterals. The borrowers' weak credit awareness leads to their default on loan and rural bank's credit risk.

If borrowers are not punished for default, it will have a "broken window effect", which means that people will be induced to emulate if bad behaviors are allowed to exist. So one borrower's defaulting the loan will provoke other borrowers' imitation, then will lead to "herding effect". This would result in fund chain issues of rural bank, causing large scale credit risk and liquidity risk.

At the moment, some depositors are exposed to credit risk. Since Chinese farmers form a close network due to factors such as blood relations and acquaintance society, information inside the group is so complete that any negative information about rural bank spreads quickly, then accelerates the risk information spread and may leads to bank runs.

\section{RURAL BANK'S CREDIT RISK TRANSMISSION EFFECT AND ITS TRANSMISSION BLOCKING BASED ON GAME ANALYSIS}

There are three significant risk nodes in rural bank's credit risk transmission: whether farmers use loan funds for contracted purposes, whether they choose to default the loan actively because of shortage of effective collaterals even if they succeed in investment, whether one borrower's not being punished for default causes other borrowers' imitation. The three risk nodes are corresponded to Domino effect, the coupling effect and the broken window effect in risk transmission. Game analyses are applied to the three effects as followed.

\section{A. Domino Effect in Credit Risk Transmission of Rural Bank}

Domino effect refers to a tiny initial energy leading to a series of chain reactions and significant change of the system. Key point to prevent Domino dumping is human behavior.

\section{B. Performance of Domino Effect in Credit Risk Transmission}

A risk node in rural bank's credit risk system is stimulated by risk sources. When the physical amount of risk is accumulated to a certain degree that exceeds risk threshold, credit risk attached to carriers will be transmitted to the next node and consequently lead to outbreak of credit risk by recipients. It would subsequently influence rural bank, other rural financial institutions, even the real economy, which reflects Domino effect.

Three conditions contributes to the occurrence of Domino effect, namely risk sources, the physical amount of risk exceeding risk threshold and the relevance among risk nodes. Through above analysis, we are aware that if a borrower is induced by speculation information, he would breach the contract to invest other high return project, which generally has high risk. This would trigger credit risk, while it is not the end of negative influences that speculation behaviors could exert on rural bank and real economy. Due to geologically native factors, one borrower's default may lead to other borrowers' imitation. In view of the weakness of agricultural production, non-performing loan ratio would increase rapidly if a large number of high risk investments fail.

\section{Game analysis on blocking Domino effect}

The key to block rural bank's credit risk transmission lies in tracking the loan usage to prevent borrowers from being induced by speculation information on high-risk projects. The strategy to block Domino effect is either to prevent the first card from falling down or to take one card in the middle to prevent the rest to collapse. In credit risk transmission, the strategy is to conduct strict pre-loan review and regular loan review, and strengthen punishment on defaulters. We use game theory to analyze this strategy as followed.

Assume that the borrower's own funds is L, the amount of loan is $\mathrm{K}$ with period $\mathrm{T}$ and simple interest rate $\mathrm{r}$. The probability that borrowers invest un-contracted projects is $\mathrm{P}$, therefore the probability of complying with the contract is 1-P. The concealment cost is $K_{3}=\rho_{3} K$, where $\rho_{3}$ represents the cost rate to conceal the usage of loan funds. Rural bank has the right to investigate the loan's usage, with a probability of $\eta$ to conduct investigation and a cost of $K_{2}=\rho_{2} K$, where $\rho_{2}$ represents the cost rate for the bank to conduct investigation, supposing that investigating efficiency is $100 \%$. For the loan that is properly used, the success probability of the project is $\theta_{1}$ with return rate $\rho_{1}$, hence its failure probability is $1-\theta_{1}$ with return rate 0 . The loan may be switched to un-contracted project, supposing its success probability is $\theta_{2}$ with a return rate $\rho_{1}^{\prime}$, and then its 
failure probability is $1-\theta_{2}$ with return rate 0 . We ignore tax

factors for calculation simplicity. The game tree of rural bank

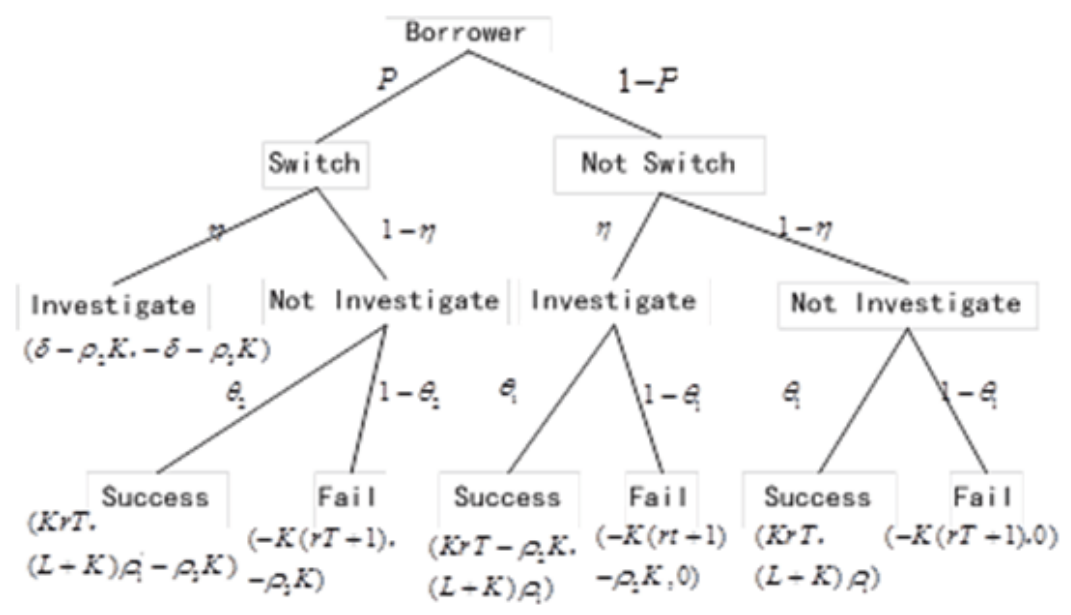

Figure.1. Game tree of rural bank and borrower

According to Figure 1, expected payoff of borrowers' switching to un-contracted project is:

$$
\begin{aligned}
\pi_{2} & =\eta\left(-\delta-\rho_{3} K\right)+(1-\eta)\left\{\theta_{2}\left[(L+K) \rho_{1}^{\prime}-\rho_{3} K\right]-\left(1-\theta_{2}\right) \rho_{3} K\right\} \\
& =(1-\eta) \theta_{2}(L+K) \rho_{1}^{\prime}-\eta \delta-\rho_{3} K
\end{aligned}
$$

Borrowers' expected payoff if not switching is:

$$
\pi_{1}=\eta \theta_{1}(L+K) \rho_{1}+(1-\eta) \theta_{1}(L+K) \rho_{1}=\theta_{1}(L+K) \rho_{1} .
$$

In order for borrowers to comply with loan contracts, we need $\pi_{1}>\pi_{2}$, hence

$$
\begin{gathered}
\theta_{1}(L+K) \rho_{1}>(1-\eta) \theta_{2}(L+K) \rho_{1}^{\prime}-\eta \delta-\rho_{3} K . \\
\rho_{3}>\frac{1}{K}\left\{\left[(1-\eta) \theta_{2} \rho_{1}^{\prime}-\theta_{1} \rho_{1}\right](L+K)-\eta \delta\right\} .
\end{gathered}
$$

If certain methods are adopted to increase the transaction cost, it can reduce the default use probability of the loan. The borrowers' expected payoff when breaching the contract is less than that when they comply with the contract if Eq.4 is satisfied. Under the circumstance borrowers would choose to respect the contract.

Based on analysis above, conducting strict pre-loan review and regular loan review and severely punishing defaulters contributes to lower the probability of credit risk. Namely preventing the first card from falling down or taking one card in the middle can block Domino effect in credit risk transmission of rural bank.

\section{The Coupling Effect in Credit Risk Transmission of Rural Bank}

Coupling refers to the phenomenon that two or more systems influence mutually through interactions. The interaction is due to the matching relationship between different risk sources and the correlation among the nodes in credit business process. The matching degree among the credit risk sources and the correlation degree among the risk nodes together determine the coupling effect of rural bank's credit risk transmission. 


\section{E. Performance of Coupling Effect in Credit Risk} Transmission

Variance is used to depict risk status in rural bank's credit system:

$$
\sigma^{2}=\sum_{i}^{n} \sum_{j}^{n} k_{i} k_{j} \sigma_{i} \sigma_{j} \rho_{i j}
$$

$\sigma^{2}$ is total risk value in rural bank's credit system. $\sigma_{i}$ is the physical amount of risk at credit risk node $i$ with a weight of $k_{i}$, and $\sigma_{j}$ is the physical amount of risk at credit risk node $\mathrm{j}$ with a weight of $k_{j}$. $\rho_{i j}$ refers to the correlation coefficient between node $\mathrm{i}$ and $\mathrm{j}$.

If $\rho_{i j}>0$, which means that there is a positive correlation between two nodes, a strong coupling effect exists in credit risk transmission process. In this case, risk at the two nodes is superposed and amplified. If $\rho_{i j}=0$, which means that $\mathrm{i}$ and $\mathrm{j}$ are two independent nodes, there will be no large fluctuation of risk strength during the risk transmission process. If $\rho_{i j}<0$, which means that there is a negative correlation between two nodes, a weak coupling effect exists in credit risk transmission process. In this case, risk level of the system after coupling is less than that before coupling.

\section{F. Game Analysis on Blocking the Strong Coupling Effect}

The management of coupling effect in rural bank's credit risk transmission is to attenuate strong coupling effect and to intensify weak coupling effect. Assume that external risk, for instance market risk and policy risk, has occurred. We will attempt to require additional collaterals through loan covenants change to attenuate the strong coupling effect and to reduce the probability of default. Assume that A represents a farmer and B represents a rural bank. The farmer obtains loan with principal $\mathrm{M}$, interest rate $\mathrm{r}$, maturity $\mathrm{t}$ in lump sum. The interest is calculated with continuous compounding method, therefore at maturity loan interest is $M e^{r t}$. Rural bank chooses to approve the farmer's loan application with probability of $\eta$, and the farmer will pay off on time with probability of $\theta$. The credit process of the game tree without collaterals is illustrated as Fig. 2.

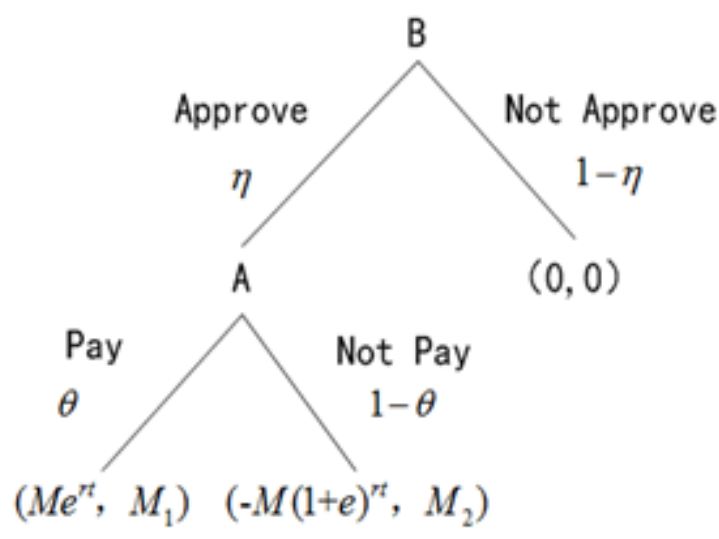

Figure.2. Game tree of rural bank and borrower without collaterals

Payoff of the rural bank and the farmer is 0 if the bank does not approve loan application. If the application is approved and the farmer pays off his debt on time, the bank will get the interest $M e^{r t}$ and the farmer will obtain an investment return of $M_{1}$ at maturity. If the farmer defaults on loan, rural bank will lose principal and interest with a total amount of $M(1+e)^{r t}$ while the farmer's payoff is $M_{2}$.

Expected payoff of farmer A is:

$$
E(A)_{1}=\eta \times\left[\theta \times M_{1}+(1-\theta) \times M_{2}\right]
$$

Expected payoff of bank B is:

$$
E\left(B_{1}\right)=\eta \times\left[\theta \times M e^{r t}-(1-\theta) \times M(1+e)^{r t}\right]=(2 \theta-1) \eta M e^{r t}
$$

We conclude from equation (7) that only if $\theta>0.5$ would bank B approve the loan application since it obtains a positive expected payoff.

If collaterals with a realizable value of $\mathrm{C}$ is provided with farmer A's loan application, the game tree of credit process is illustrated as Figure. 3. 


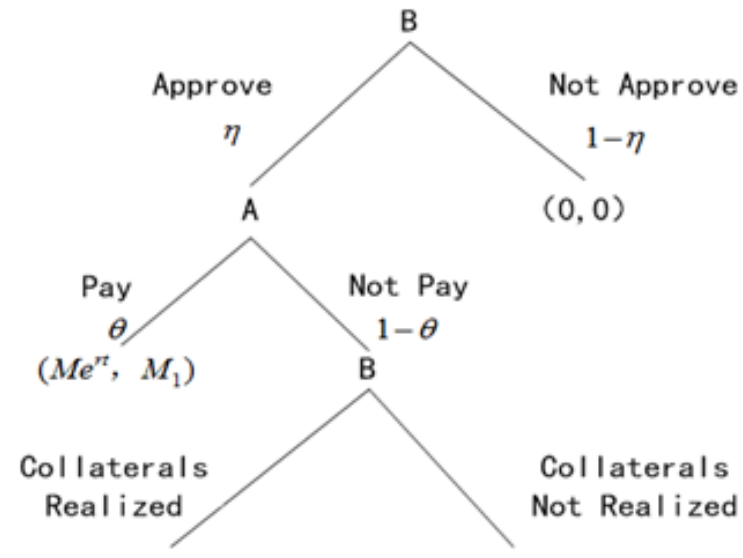

Figure.3. Fig. 3 Game tree of rural bank and brower with collaterals difference lies in the fact that rural bank $B$ can realize collaterals when provided if farmer A defaults his debt. If farmer A does not pay off his debt on time, rural bank B will absolutely realize collaterals to obtain a positive return of $\mathrm{C}$ since the bank has entire disposal of collaterals. Therefore if farmer A provides collaterals when he applies for loan but defaults on it at maturity, payoff matrix will be $\left(C-M(1+e)^{r t}, M_{3}\right)$. Denote the payoff of farmer A by $M_{3}$ and we have $M_{3}<M_{2}$.

Expected payoff of farmer $\mathrm{A}$ is:

$$
E(A)_{2}=\eta \times\left[\theta \times M_{1}+(1-\theta) \times M_{3}\right]
$$

Expected payoff of rural bank B is:

There are no differences between payoff with collaterals and payoff without collaterals if rural bank B chooses not to approve loan application or if rural bank B approves application and farmer $\mathrm{A}$ pays off debt on time. The

$$
\begin{aligned}
E(B)_{2}= & \eta \times\left\{\theta \times M e^{r t}+(1-\theta) \times\left[C-M(1+e)^{r t}\right]\right\} \\
& =(2 \theta-1) \eta M e^{r t}+\eta C(1-\theta)
\end{aligned}
$$

Obviously, we have $E(B)_{2}-E(B)_{1}=\eta C(1-\theta)$. Since $0<\theta<1$, then $E(B)_{2}>E(B)_{1}$. Rural bank will have a higher expected payoff when collaterals are provided in loan application.

From above analysis, the strategy that rural bank requires additional collaterals will produce weak coupling effect to reduce the strength of credit risk transmission, thereby can reduce rural bank's credit risk.

\section{G. The Broken Window Effect in Credit Risk Transmission of Rural Bank}

The broken window effect refers to the fact that indulging bad behaviors will encourage people to imitate or become aggravated. Ignorant of the first broken window is a hint that people may disobey regulations to break more windows, which reveals herd mentality in an atmosphere full of implications.

\section{H. Performance of Broken Window Effect in Credit Risk} Transmission

During credit risk transmission from inside to outside the bank, the broken window effect will be generated. If rural bank fails to severely punish the first borrower's defaulting, there will be an implication that defaulters will not be punished and the cost of "breaking window" is extremely low. Then other borrowers will imitate this behavior to default the loans deliberately. The broken window effect is an exogenous demonstration effect.
There is also an endogenous demonstration effect in rural bank's credit risk transmission process. When the bank's employee does not conduct strict loan review or neglect his duty, and if he is not punished, this non-compliant behavior will result in other employees' imitation and would lead to credit risk for the bank.

\section{Game Analysis on Blocking Broken Window Effect}

The key to block broken window effect or credit risk transmission of rural bank lies in to review the proceeds of borrowers' loan projects and punish the dishonest borrowers. Assume that the borrower's own fund is L and loan amount is $\mathrm{K}$ with simple interest rate $\mathrm{r}$ and maturity $\mathrm{T}$. The probability of the borrower's investment to succeed is $\theta$ and the rate of return is $\rho_{1}$. Hence payoff of the borrower is:

$$
\left\{\begin{array}{c}
(L+K) \rho_{1}, \theta \\
0,1-\theta
\end{array}\right.
$$

Expected payoff of the borrower is $(L+K) \rho_{1} \theta$. If the borrower's investment succeeds but he conceals his income to avoid repayment, supposing his concealing cost is $K_{3}=\rho_{3} K$, rural bank will punish the borrower for a fine $\delta$. The bank's post-loan review cost is $K_{2}=\rho_{2} K$, assuming that reviewing efficiency is $100 \%$. The probability of the borrower's being dishonest is $\mathrm{Q}$ and the probability of rural 
bank's conducting a review is $\mathrm{P}$. We ignore tax factors for calculation simplicity. The game tree of rural bank and borrowers is illustrated as Figure. 4.

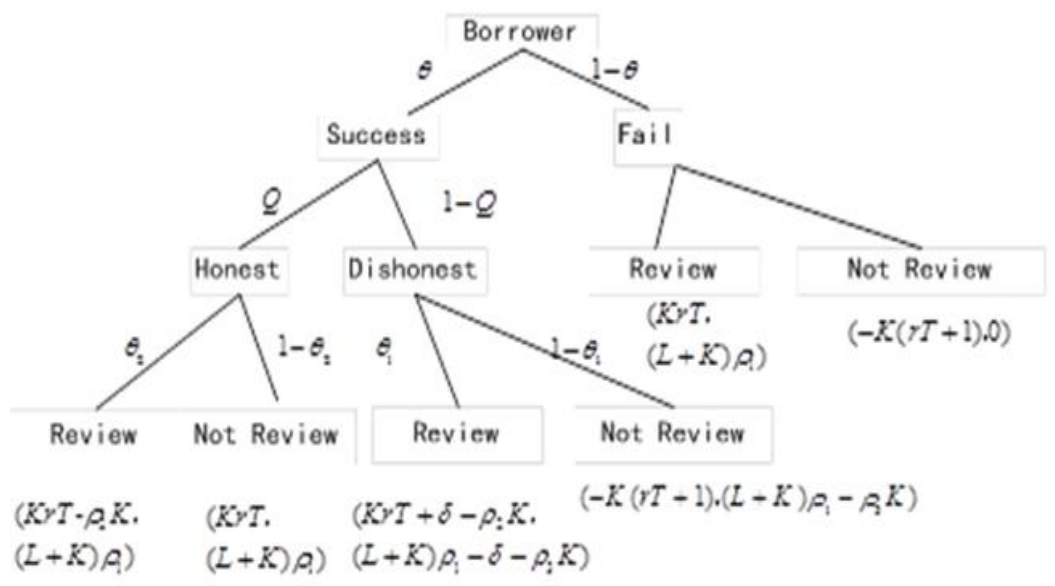

Figure.4. Game tree of the borrower and rural bank with review mechanism

Expected payoff of rural bank with review mechanism is:

$$
\pi_{1}=\theta\left[(1-Q)\left(K r T-\rho_{2} K\right)+Q\left(K r T-\rho_{2} K+\delta\right)\right]-(1-\theta)\left[K(r T+1)+\rho_{2} K\right]
$$

Expected payoff of rural bank without review mechanism is:

$$
\pi_{2}=\theta[(1-Q) K r T-Q K(r T+1)]-(1-\theta) K(r T+1)
$$

Expected payoff of a dishonest borrower is:

$$
\begin{aligned}
\pi_{3} & =P\left[\rho_{1}(L+K)-\rho_{3} K-\delta\right]+(1-P)\left[\rho_{1}(L+K)-\rho_{3} K\right] \\
& =\rho_{1}(L+K)-\rho_{3} K-P \delta
\end{aligned}
$$

Expected payoff of an honest borrower is:

$$
\pi_{4}=P \rho_{1}(L+K)+(1-P) \rho_{1}(L+K)=\rho_{1}(L+K)
$$

Obviously we have $\pi_{4}>\pi_{3}$ due to the post-loan review and punishing mechanism for concealing income. That is to say, expected return under concealment strategy is less than that under honest strategy, so the borrower will choose honest.

From above analysis, we can conclude that punishment on not repaying loan on time would decrease a borrower's expect payoff. Consequently the borrower will keep honest and pay principal and interest on time, and other borrowers will act in the same. Therefore the broken window effect is prevented from the source.

\section{SUGGESTIONS ON STRENGTHENING CREDIT RISK MANAGEMENT OF RURAL BANK}

We give some suggestions on rural bank's credit risk management based on previous analysis as follows.

\section{A. Strictly Implementing Pre-loan Investigation Mechanism}

Pre-loan investigation refers to the bank's assessing a borrower's credit status at the beginning of his application, including legitimacy of the application, safety of the loan's usage and the profitability of loan projects, especially, qualifications of the borrower, collateral validity, financial management ability, operation status and repayment ability, etc. There are many ways to conduct pre-loan investigation, including field investigation, search survey and commissioned investigation. Since rural bank's business is in a small local area, field investigation is the most suitable one. Employees in the rural bank should make full use of customers' geographical locality to obtain their first-hand information in order to guarantee the authenticity and integrity of customers' credit information.

\section{B. Perfecting the Loan Guarantee System of Rural Bank}

Provisions of existing guarantee law lead to the customers' lacking of valid collaterals for loans. We propose the following solutions. Firstly, the valid collaterals may be extended to include the management right of rural contracted land, ownership of forests, use right of qualified countryside homestead and farmhouses. These assets should be used to secure farmer's financing. Secondly, a guarantee company, funded by the government with equity participation of 
farmers and small and medium-sized enterprises, should be established to encourage the innovation of guarantee modes. Thirdly, financial innovation related to order agriculture should be promoted.

\section{Strengthening Post-loan Management System of Rural Bank}

Firstly, during the loan period, rural bank employees should always pay attention to the progress of loan projects, the borrower's financial situation and market price of collaterals, and notice whether the possible changes have bad effect the on loan projects. Secondly, a dishonest disciplinary mechanism should be constructed to increase transaction cost of dishonest behavior and decrease default probability. A database about customers' credit information should be constructed and shared within the region. An internal disciplinary system should be established simultaneously to ensure managers and employees' compliance with regulations. Once dishonest behaviors occur, it would be recorded in the profession credit behavior database so that managers and employees are constraint to consciously maintain their own credit.

\section{ACKNOWLEDGMENT}

This paper is supported by National Social Science Fund in China: Study on the Innovation of Credit Risk Management for Village Bank under Fragile Credit Environment (Grant No. 14BGL185).

\section{REFERENCES}

[1] S.M. Frederic, "Understanding Financial Crises: A Developing Country Perspective", Annual World Bank Conference on Development Economics, 1996.

[2] M. Vives, "Range of Practice in Bank's Internal Ratings System", A Discussion Peer by the Basel Committee on Banking Supervision, January, 2007.

[3] F. Wang, "Study on Quantitative Management of Credit Risk of Rural Banks", Management and Techonology of Small and Medium Enterprises, vol.30, pp. 66-67, 2013.

[4] K.N. Fang, G.J. Zhang, H.Y. Zhang, "Credit Risk Warning Method Based on Lasso-logistic Model", The Journal of Quantitative \& Technical Economics, pp.125-136, Feb. 2014.

[5] Z.Y. Lei, Thoughts on the Prevention of Credit Risk of Rural Bank, Regional Financial Research, Jan., 2013, pp.73-75.

[6] D.D. Wang, "Credit Management and Innovation Development Research of Rural Bank of Henan Province", Rural Finance Research, Jan., 2016, pp.62-65.

[7] T. Balg, I. Goldfajn, Financial Market Contagion in the Asian Crisis, IMF Staff Papers, vol.46, 1999, pp.167-175.

[8] G.L. Kaminsky, C.M. Reinhart, "On Crises, Contagion, and Confusion", Journal of International Economics, vol.51, pp.145-168, 2000

[9] H.F. Gu, "Research on the Transmission and Management of Credit Risk of Commercial Banks under the Cooperation of Bank and Insurance", International Finance Research, pp.58-66, Feb. 2013.

[10] W.J. Bai, N.N. Zhang, "Research on the Transmission Mechanism of Interest Rate Risk in Life Insurance Company", Hainan Finance, pp.18-22, Dec., 2013.

[11] Y.D. Wang, J.W. Sun, "Research on Enterprises' Conduction Mechanism of Innovation Fund Allocation Risk", Science-Technology and Management, vol16, pp.94-98, 2014.

[12] Y. Zhang, M.X. Zhu, "Conduction of Financial Risk under Open Conditions: Requirements, Paths and Mechanism", Communication of Finance and Accounting, pp. 113-115, Feb. 2015. 